\title{
INFLUÊNCIA DO CONTEXTO SILÁBICO DA PALAVRA \\ NO JULGAMENTO PERCEPTIVO-AUDITIVO DO CECEIO PRODUZIDO POR PRÉ-ESCOLARES
}

\author{
Influence of syllable context in the auditory perceptual judgment \\ of lisping in preschool children
}

\begin{abstract}
Viviane Cristina de Castro Marino (1), Isabela Marchioni dos Santos (2), Eliana Maria Gradim Fabron (3), Jeniffer de Cássia Rillo Dutka ${ }^{(4)}$, Julio de Araújo Gurgel ${ }^{(5)}$, Larissa Cristina Berti ${ }^{(6)}$
\end{abstract}

\begin{abstract}
RESUMO
Objetivos: investigar a ocorrência do ceceio em fricativas produzidas por crianças com alterações oclusais e analisar a influência do contexto silábico da fricativa no julgamento auditivo do ceceio. Método: estudo prospectivo, em que as gravações de 428 palavras, produzidas por 15 crianças (idade média de 5 anos e 1 mês) foram julgadas auditivamente por três fonoaudiólogos com experiência no julgamento de alterações de fala. As palavras utilizadas foram constituídas pelas consoantes fricativas não vozeadas, alveolar e pós-alveolar, inseridas em posição tônica, precedida das vogais [i, a, u]. Obteve-se concordância intra-juiz (quase perfeita) e inter-juiz (total, 100\%) previamente à análise dos aspectos de interesse. Resultados: embora presente na fala de todas as crianças, identificou-se ceceio em $25,23 \%$ do total das palavras. Houve aumento significante do ceceio para: (a) fricativa alveolar em ataque inicial, (b) fricativa alveolar em ataque inicial em relação à coda medial $(p=0,001)$ e (c) fricativa alveolar em relação à fricativa pós- alveolar $(p<0,001)$. Não se observou diminuição do ceceio em relação às vogais co-articuladas. Conclusão: a ocorrência do ceceio é dependente do contexto silábico, (com maior ocorrência na fricativa alveolar, em posição de ataque inicial), devendo o mesmo ser considerado para fins clínicos e de pesquisa sobre o ceceio.
\end{abstract}

DESCRITORES: Fala; Criança; Pré-escolar

(1) Fonoaudióloga; Professor assistente doutor da Faculdade de Filosofia e Ciências da Universidade Estadual Paulista UNESP, Marília, SP, Brasil; Doutor em Communication Sciences and Disorders pela Universidade da Flórida, EUA.

(2) Fonoaudióloga, Graduada em Fonoaudiologia pela Faculdade de Filosofia e Ciências - UNESP, Marília, SP, Brasil.

(3) Fonoaudióloga; Professor assistente doutor da Faculdade de Filosofia e Ciências da Universidade Estadual Paulista UNESP, Marília, SP, Brasil; Doutor em Educação pela UNESP, Marília.

(4) Fonoaudióloga; Professor assistente doutor do Curso de Fonoaudiologia da Faculdade de Odontologia de Bauru e do Programa de Pós-Graduação do Hospital de Reabilitação de Anomalias Craniofaciais da Universidade de São Paulo - USP, Bauru, SP, Brasil; Doutor em Communication Sciences and Disorders pela Universidade da Flórida, EUA.

(5) Ortodontista; Professor assistente doutor da Faculdade de Filosofia e Ciências da Universidade Estadual Paulista UNESP, Marília, SP, Brasil; Doutor em Ortodontia e Odontologia em Saúde Coletiva pela USP, Bauru.

\section{INTRODUÇÃO}

O equilíbrio entre as estruturas estomatognáticas é considerado de fundamental importância para a produção das consoantes fricativas ${ }^{1}$, que são aquelas caracterizadas pela passagem do fluxo de ar por um estreitamento suficiente para gerar turbulência na aérea na cavidade oral ${ }^{2}$. As consoantes fricativas alveolares ([s], [z]), em particular, são produzidas com constrição parcial da corrente aérea entre o ápice da língua e o alvéolo ${ }^{3}$, sendo para isso necessário que a borda da língua assuma

(6) Fonoaudióloga; Professor assistente doutor da Faculdade de Filosofia e Ciências da Universidade Estadual Paulista UNESP, Marília, SP, Brasil; Doutor em Linguistica pela UNICAMP, Campinas.

Conflito de interesses: inexistente 
forma e posição específicas e extremamente precisas para que o fluxo aéreo possa ser direcionado para os incisivos inferiores ${ }^{1,4}$. No entanto, quando ocorrem modificações nestas condições, o som pode ser produzido de forma distinta do esperado ${ }^{1,5}$, podendo apresentar-se distorcido ${ }^{6}$. Da mesma forma, as consoantes fricativas alveopalatais ou pós-alveolares ([], [3]), resultantes da constrição parcial da corrente aérea entre a parte anterior da língua e a parte média do palato duro ${ }^{3}$, também podem ser produzidas de forma alterada, quando a língua posiciona-se incorretamente durante sua produção ${ }^{7}$.

As consoantes fricativas são consideradas sons suscetíveis às distorções. Na literatura, há divergências de nomenclatura para referir-se às alterações encontradas nestas consoantes ${ }^{4}$. No entanto, o termo ceceio é comumente utilizado para referir-se à produção distorcida das fricativas alveolares. De acordo com o Comitê de Motricidade Orofacial da Sociedade Brasileira de Fonoaudiologia ${ }^{7}$, o termo ceceio é definido como a pronúncia dos fones [s] e [z] como interdentais com a língua anteriorizada. Já o termo ceceio lateral é definido como posição incorreta da língua na produção dos fones [s], [z], [] e [3] com a língua posteriorizada e com a possibilidade de ocorrência de escape de ar.

Estudos indicam que o ceceio pode ser decorrente de vários fatores, dentre eles, das modificações das estruturas ou do espaço intra-oral ${ }^{1,4}$. Alguns estudos, em particular, descrevem que a mordida aberta anterior, quando presente, pode influenciar a produção da consoante alveolar ${ }^{5}$, levando a uma alteração na fricção dessa consoante ${ }^{1,4,6,8,9}$. Outros estudiosos apontam uma possível interferência da mordida aberta lateral ${ }^{1}$ e da mordida cruzada na produção da fricativa alveolar ${ }^{5}$. Embora estudos indiquem que alterações oclusais possam resultar em um prejuízo na produção das consoantes fricativas, esta relação nem sempre é observada, ${ }^{5,6,10,11}$.

Alguns autores ${ }^{12}$ concluem, portanto, que existem muitas dificuldades em comprovar, sistematicamente, a relação entre alterações estruturais e alterações de fala, mencionando, por exemplo, que a etiologia das alterações de fala é variável e, ainda, que um mesmo fator etiológico resulta em características clínicas diferentes, além da grande variabilidade que existe nos graus de severidade nas alterações oclusais. Tal variabilidade foi recentemente observada em um estudo sobre alterações da fala associadas à fissura labiopalatina ${ }^{11}$. Também é reportado na literatura que alterações na forma ou função das estruturas estomatognáticas podem não levar à alteração na produção da fala se o indivíduo realizar uma adaptação eficiente a estas condições ${ }^{13}$. Por estas razões, alguns estudos apontam a má-oclusão como fatores de risco para o ceceio $^{4,6}$, mas não como um fator determinante para o mesmo. Alguns estudiosos ainda enfatizam que o ceceio pode estar relacionado à presença de cavidade oral pequena para o tamanho da língua resultando na projeção da mesma durante a produção do som, bem como pode estar relacionado ao fato da criança estar na fase de aquisição e de aperfeiçoamento de seu sistema fonológico, desenvolvendo seu padrão articulatório ${ }^{6}$.

Frente ao exposto, observa-se que o estudo do ceceio requer a consideração de vários aspectos (condições oclusais, idade/gênero, fase de aquisição dos sons) para o seu maior entendimento. Dentre estes aspectos, destaca-se a interferência de fatores linguísticos na produção do ceceio. Um estudo, particularmente, investigou a correlação entre o ceceio e a tonicidade da sílaba com [s] em diferentes contextos silábicos, em 16 sujeitos na faixa etária entre 5 e 19 anos, de ambos os sexos, que se encontravam em terapia fonoaudiológica por apresentarem ceceio no fone [s] ${ }^{1}$. A maioria (75\%) dos sujeitos pesquisados apresentava ceceio anterior enquanto os demais apresentaram ceceio lateral. Estes sujeitos foram submetidos a teste de fala constituído da emissão de palavras com [s] nas posições iniciais, finais e dentro da palavra, em sílabas átonas e tônicas seguidas das vogais [a], [e], [i], [o] e [u] e suas produções foram analisadas por duas fonoaudiólogas, por meio de avaliação perceptivo-auditiva e visual. Os resultados obtidos indicaram que houve diminuição significante do ceceio nas posições de ataque inicial e medial em relação às posições coda medial e final, porém não foi observada diminuição do ceceio em relação à tonicidade da sílaba ou à co-articulação com as diferentes vogais. Os autores concluíram que a tonicidade silábica e a co-articulação com as diferentes vogais não alteram a incidência do ceceio, mas que as posições iniciais da sílaba parecem ser facilitadoras na produção de [s]. A variável posição da sílaba, segundo os autores, deve ser considerada na escolha do recurso e material a ser utilizado em terapia. Os autores salientaram ainda a necessidade de dar continuidade a estudos desta natureza, integrando um número maior de sujeitos, reduzindo as variáveis, aprimorando a padronização das amostras de fala, bem como eliminando possíveis interferências, como tempo de terapia e diferença de idade entre os sujeitos avaliados.

$\mathrm{Na}$ literatura brasileira, de uma forma geral, são restritos os estudos que possibilitam um maior entendimento da influência do contexto silábico da palavra no julgamento do ceceio, a partir de produções de fala de crianças, em contexto de fala padronizado. Além disso, verifica-se que informações 
sobre o ceceio na fricativa pós-alveolares também são escassas, embora seja reportado que a produção desta consoante pode estar comprometida devido ao posicionamento alterado da língua (posteriorizada e com a possibilidade de ocorrência de escape de ar) ${ }^{7}$. Assim, informações adicionais sobre a influência do contexto silábico na produção e no julgamento do ceceio podem favorecer sua identificação, bem como nortear o estabelecimento do processo terapêutico. Vale ressaltar que a influência do contexto silábico na produção das fricativas por sujeitos com fala típica foi demonstrada previamente, a partir de informações derivadas da análise acústica. Por exemplo, uma investigação das fricativas desvozeadas (alveolar e pós-alveolar), em posição de ataque silábico inicial, produzidas por crianças brasileiras com aquisição fonológica típica e desviante, mostrou que a fricativa alveolar apresenta frequências de ressonâncias mais altas do que a pós-alveolar, fato verificado por meio dos parâmetros acústicos pico espectral, centróide e assimetria. Ainda, a trajetória formântica de F2 da vogal [a] que precede as fricativas foi um parâmetro que diferenciou o ponto articulatório das fricativas alveolares e pós-alveolares produzidas pelas crianças com fala típica ${ }^{14}$. Frente a estes dados, hipotetiza-se que na presença do ceceio o mesmo poderia ser mais saliente (e, portanto, mais percebido), já que há um maior reforço das frequências mais altas na fricativa alveolar do que na pós-alveolar. Com relação à posição que a fricativa alveolar ocupa no interior da sílaba, em posição de ataque, há, tipicamente, uma maior duração quando comparada à posição de coda silábica ${ }^{15}$.

Além dos aspectos relacionados ao falante (como modificações das estruturas ou do espaço intra-oral, por exemplo) e aspectos linguísticos relacionados ao estímulo de fala (como posição que a sílaba ocupa na palavra, por exemplo), outra variável a ser considerada em estudos que reportam resultados de fala é a forma como é realizado o julgamento perceptivo-auditivo da variável de interesse. Estudos sobre os vários desvios de fala apontaram para a importância de se considerar como as produções de fala são julgadas para fins clínicos e de pesquisa, já que o julgamento pode ser favorecido tanto pelas informações auditivas quanto visuais ${ }^{16}$ e também demais variáveis envolvidas na tarefa de atribuir um julgamento perceptivo-auditivo. Neste sentido, informações sobre os juízes (treinados ou sem experiência na avaliação da fala), quantidade de juízes envolvidos na tarefa e mensuração do grau de concordância dos julgamentos são aspectos considerados cruciais para permitir a análise das variáveis de interesse em estudos envolvendo fala patológica ${ }^{17}$. Ainda, o uso de gravações que permitam repetições da mesma amostra de fala para serem julgadas por um mesmo juiz também é apontado como uma variável importante em pesquisa e tem sido empregada em estudos que investigam o efeito temporal do uso de aparelhos linguais fixos na produção de consoantes ${ }^{18}$.

Considerando que vários aspectos podem influenciar na produção e identificação do ceceio, os objetivos deste estudo foram investigar a ocorrência do ceceio em fricativas produzidas por crianças com alterações oclusais e analisar a influência do contexto silábico da fricativa no julgamento auditivo do ceceio. Particularmente, foi de interesse investigar se o ceceio difere (a) entre as fricativas, alveolares e pós-alveolares, (b) se é dependente do contexto silábico, na fricativa alveolar e (c) se é dependente do contexto vocálico em ambas, fricativas alveolares e pós-alveolares.

\section{MÉTODO}

Foram selecionadas para o presente estudo 15 crianças, com faixa etária entre 5 e 6 anos (média de 5 anos e 1 mês), de ambos os gêneros. Essas crianças estudavam em uma Escola Municipal de Educação Infantil, no período integral, pertencente ao município de Marília (SP). Todas as crianças selecionadas para o estudo apresentavam desenvolvimento típico de linguagem, com aquisição fonológica completa, bem como apresentaram ceceio em consoantes fricativas (alveolares e/ou pós-alveolares), identificados durante triagem fonoaudiológica. Das 15 crianças selecionadas (9 do gênero feminino e 6 do masculino), seis encontram na dentadura decídua e 9 no primeiro período transitório da dentadura mista. Todas as crianças apresentavam alterações oclusais, identificadas a partir de avaliação clínica, por um ortodontista. Nenhuma das crianças selecionadas recebeu terapia fonoaudiológica e/ou tratamento ortodôntico previamente à data da coleta de dado.

As produções da fala analisadas no presente estudo foram extraídas de um banco de dados pertencentes ao Grupo de Pesquisa "Estudos sobre a linguagem", que é composto por gravações de todo o sistema fonológico de pré-escolares, a partir do uso do Instrumento de Avaliação de Fala para Análise Acústica (IAFAC) baseado em critérios linguísticos ${ }^{19}$. Para a constituição deste banco de dados, foram solicitadas a cada criança, na ocasião das gravações, cinco repetições de cada uma das palavras do IAFAC, inseridas numa frase veículo, que incluíam as 19 consoantes do Português Brasileiro na posição de ataque silábico, além das quatro possibilidades de coda silábica. Essas produções 
foram gravadas de forma aleatória e em dias alternados de um mesmo mês, numa cabine acústica instalada na própria instituição, utilizando equipamento digital de alta fidelidade (Gravador digital MARANTZ, microfone unidirecional Shure).

Para o presente estudo, deste banco de dados, somente as gravações das frases correspondentes às fricativas alveolares e pós-alveolares da população selecionada foram de interesse. Assim, o corpus utilizado para os dados perceptivos foi composto por nove palavras dissílabas paroxítonas da língua ("chique, chave, chuva", "cica, sapo, suco", "lista, pasta, cuspe") que combinam as fricativas coronais (alveolares e pós-alveolares) não vozeadas com as vogais [i], [a] e [u] na posição acentuada. Já a segunda sílaba das palavras foi composta por sons obstruintes. Essas palavras foram inseridas na frase-veículo "Fala __ bem bonito". O uso da frase veículo teve como objetivos favorecer um maior controle da curva entonacional da produção de cada palavra do corpus, tentando, assim, evitar a curva ascendente característica da produção obtida por meio de produção/repetição isolada em forma de lista de palavras, favorecendo o julgamento do ouvinte da fricativa de interesse.

As gravações de interesse para o presente estudo foram editadas, utilizando-se o software PRAAT $5.0^{20}$ e posteriormente armazenadas em um DVD, usando o programa Nero Express. Neste DVD, as frases produzidas pelas crianças foram distribuídas aleatoriamente. Considerando que do total do material gravado foi necessário desprezar algumas frases devido à qualidade da gravação, foram selecionadas 635 frases para o presente estudo. Desse total, 143 frases (20\% do total das frases), escoIhidas aleatoriamente, foram duplicadas e inseridas também aleatoriamente na edição, para posterior análise de concordância intra-juízes, totalizando $778(635+143)$ frases que os juízes deveriam julgar para o presente estudo.

Os julgamentos foram feitos independentemente, por três fonoaudiólogas com experiência na área de fala, utilizando o programa Windows Media Player (Microsoft). As fonoaudiólogas foram instruídas a julgar auditivamente se, durante a produção das frases, o segmento fricativo foi produzido conforme o alvo (ausência de ceceio) ou se ocorreu ceceio (ou seja, quando o segmento fricativo foi produzido com algum tipo de distorção). Após ouvirem cada frase, as fonoaudiólogas marcaram uma das alternativas (alvo ou ceceio) para cada uma das amostras de fala avaliadas, em uma planilha pré-elaborada para este fim. Vale ressaltar que não foi solicitada a caracterização do tipo de ceceio, mas sim a presença ou ausência do mesmo, a partir de seu julgamento auditivo. Nestes julgamentos, observou-se que o ceceio esteve presente em todas as crianças, em pelo menos uma de suas produções, confirmando uma dos critérios de inclusão deste estudo (apresentar ceceio na triagem fonoaudiológica).

Quanto à concordância intra-juiz, das 143 frases utilizadas para verificar esta concordância, observou-se, em média, $82 \%$ de concordância para o total de amostras indicando concordância quase perfeita intra-juiz, segundo categorização de força de concordância proposta na literatura ${ }^{21}$. Considerando estes resultados, prosseguiu-se o estudo, verificando-se a concordância inter-juízes.

A presente pesquisa foi submetida e aprovada pelo Comitê de Ética e Pesquisa da Faculdade de Filosofia e Ciências - UNESP - Campus de Marília, sob o número 1384/2009.

Ainda que 635 frases tenham sido inicialmente julgadas pelos três fonoaudiólogos, foram excluídas 207 amostras (33\%) em que não houve 100\% de concordância entre os juízes. Isto é, foram mantidas no estudo as 428 amostras julgadas com $100 \%$ de concordância entre fonoaudiólogas, indicando presença ou ausência do ceceio. Aplicou-se o Teste de Qui-quadrado, com o intuito de verificar diferenças entre as categorias de fricativas estudadas. Aplicou-se o Teste da Razão de VerossimiIhança, com o intuito de verificar diferenças entre as distribuições das três vogais estudadas, para as variáveis de interesse. Para a averiguação das suposições, foi adotado o nível de significância de $5 \%(p<0,05)$ para todos os testes estatísticos.

\section{RESULTADOS}

De forma geral, verificou-se que o ceceio esteve presente nas fricativas produzidas por todas as crianças incluídas no estudo, sendo identificado em $25,23 \%(\mathrm{~N}=108)$ do total das palavras produzidas $(\mathrm{N}=428)$ por estas crianças. A Tabela 1 mostra a ocorrência do ceceio na fricativa alveolar, em suas duas posições (ataque inicial e coda medial), e na fricativa pós-alveolar. Ao comparar os julgamentos do ceceio entre as fricativas estudadas, observou-se aumento significante do ceceio para a fricativa alveolar em posição de ataque inicial quando comparada à fricativa alveolar em posição de coda medial e à fricativa pós-alveolar $(p<0,001)$. 
Tabela 1 - Distribuição das frequências da ausência (produção alvo) e presença do ceceio na fricativa alveolar, em suas duas posições (ataque inicial e coda medial) e na fricativa pós-alveolar

\begin{tabular}{ccccccccccc}
\hline & \multicolumn{9}{c}{ Fricativa } & \multicolumn{2}{c}{ Total } & \multicolumn{2}{c}{$\begin{array}{c}\text { Significância } \\
\text { Variável }\end{array}$} \\
\cline { 2 - 10 } & Alveolar inicial & \multicolumn{2}{c}{ Alveolar medial } & \multicolumn{2}{c}{ Pós-alveolar } & & & \\
\cline { 2 - 10 } & $\mathbf{n}$ & $\%$ & $\mathbf{N}$ & $\%$ & $\mathbf{n}$ & $\%$ & $\mathbf{n}$ & $\%$ & \\
\hline Alvo & 69 & $(52.27)$ & 91 & $(72.22)$ & 160 & $(94.11)$ & 320 & $(74.76)$ & $<0,001$ \\
Ceceio & 63 & $(47.72)$ & 35 & $(27.77)$ & 10 & $(5.88)$ & 108 & $(25.23)$ & \\
\hline Total & 132 & 100 & 126 & 100 & 170 & 100 & 428 & 100 & - \\
\hline
\end{tabular}

*Teste estatístico Qui-quadrado

A Tabela 2 mostra a ocorrência do ceceio na fricativa alveolar nas duas posições investigadas. Observou-se aumento significante do ceceio desta fricativa quando em posição de ataque inicial $(p=0,001)$.
A Tabela 3 mostra a ocorrência do ceceio para a fricativa alveolar e pós-alveolar, ambas em posição inicial da palavra. Observou-se aumento significante do ceceio para a fricativa alveolar $(p<0,001)$.

Tabela 2 - Distribuição das frequências da ausência (produção alvo) e presença do ceceio na fricativa alveolar, em suas duas posições (ataque inicial e coda medial)

\begin{tabular}{ccccccc}
\hline \multirow{2}{*}{ Variável } & \multicolumn{2}{c}{ Alveolar inicial } & \multicolumn{2}{c}{ Alveolar medial } & \multirow{2}{*}{ Significância (p) } \\
\cline { 2 - 5 } & $\mathbf{n}$ & $\%$ & $\mathbf{n}$ & $\%$ & \\
\hline Alvo & 69 & $(52.27)$ & 91 & $(72.22)$ & \multirow{2}{*}{0,001} \\
Ceceio & 63 & $(47.72)$ & 35 & $(27.77)$ & \\
\hline Total & 132 & 100 & 126 & 100 & - \\
\hline
\end{tabular}

*Teste estatístico Qui-quadrado

Tabela 3 - Distribuição das frequências da ausência (produção alvo) e presença do ceceio na fricativa alveolar e pós-alveolar, ambas na posição inicial

\begin{tabular}{cccccc}
\hline \multirow{2}{*}{ Variável } & \multicolumn{3}{c}{ Alveolar } & \multicolumn{3}{c}{ Pós-alveolar } & \multirow{2}{*}{ Significância (p) } \\
\cline { 2 - 5 } & $\mathbf{n}$ & $\%$ & $\mathbf{n}$ & $\%$ & \\
\hline Alvo & 69 & $(52.27)$ & 160 & $(94.11)$ & \multirow{2}{*}{$<0,001$} \\
Ceceio & 63 & $(47.72)$ & 10 & $(5.88)$ & \\
\hline Total & 132 & 100 & 170 & 100 & \\
\hline
\end{tabular}

*Teste estatístico Qui-quadrado

A Tabela 4 mostra a ocorrência do ceceio nas fricativas alveopalatal e alveolar (nas duas posições, ataque inicial e coda medial), quando associadas às vogais co-articuladas. Não foi verificada diferença significante na ocorrência do ceceio quando as fricativas estavam associadas às três vogais do extremo vocálico (valores de $p<0,05$ ). 
Tabela 4 - Distribuição de frequências da produção alvo e presença do ceceio, de acordo com a vogal na produção da fricativa palatal

\begin{tabular}{|c|c|c|c|c|c|}
\hline Variável & & Alvo & Ceceio & Total & Significância (p) \\
\hline \multirow{3}{*}{$\begin{array}{l}\text { Fricativa alveolar } \\
\text { ataque inicial }\end{array}$} & /i/ & $22(47.82)$ & $24(52.17)$ & $46(100)$ & \multirow{3}{*}{0,335} \\
\hline & /a/ & $20(47.61)$ & $22(52.38)$ & $42(100)$ & \\
\hline & $/ \mathrm{u} /$ & $27(61.36)$ & $17(38.63)$ & $44(100)$ & \\
\hline \multirow{3}{*}{$\begin{array}{l}\text { Fricativa alveolar } \\
\text { coda medial }\end{array}$} & /i/ & $29(70.73)$ & $12(28.57)$ & $41(100)$ & \multirow{3}{*}{0,08} \\
\hline & /a/ & $26(61.90)$ & $16(38.09)$ & $42(100)$ & \\
\hline & $/ \mathrm{u} /$ & $36(83.72)$ & $7(16.27)$ & $43(100)$ & \\
\hline \multirow{3}{*}{ Fricativa pós-alveolar } & /i/ & $65(95.58)$ & $3(4.41)$ & $68(100)$ & \multirow{3}{*}{0,335} \\
\hline & /a/ & $50(96.15)$ & $2(3.84)$ & $52(100)$ & \\
\hline & $/ \mathrm{u} /$ & $45(90.00)$ & $5(10.00)$ & $50(100)$ & \\
\hline
\end{tabular}

*Teste de Razão da Verossimilhança

\section{DISCUSSÃO}

Os resultados do presente estudo mostraram que, a partir do julgamento perceptivo-auditivo, o ceceio foi identificado em $25,23 \%(\mathrm{~N}=108)$ do total das palavras produzidas $(\mathrm{N}=428)$ por pré-escolares comalterações oclusais (Tabela 1). Embora presente na produção de todas as crianças, verificou-se que o ceceio não ocorreu em todas as palavras e nem em todas as repetições realizadas pelas crianças, mostrando variabilidade de produção inter-palavras e intra-sujeitos. Estes achados concordam com estudo prévio ${ }^{1}$ que também reportou variabilidade na ocorrência do ceceio no fone [s], ao se analisar a fricativa alveolar em contextos fonético-fonológicos controlados.

No presente estudo, ao se verificar a influência do contexto silábico da palavra na produção do ceceio, procurou-se investigar se o ceceio difere entre as fricativas, alveolares e pós-alveolares. Os resultados indicaram maior ocorrência do ceceio na fricativa alveolar em posição de ataque inicial ("cica", "sapo", "suco"), seguida na fricativa alveolar em coda medial ("lista', "pasta", "cuspe"), com menor ocorrência do ceceio para a fricativa pós-alveolar ("chique", "chave", "chuva"), na produção de pré-escolares com má-oclusão. O aumento significante do ceceio para a fricativa alveolar em posição de ataque inicial indica que o ceceio pode ser mais facilmente percebido neste contexto silábico, quando identificado pela avaliação perceptivo-auditiva, provavelmente devido às frequências de ressonância ser mais alta em [s] e principalmente nesta posição silábica. Sugere-se, portanto, para fins clínicos, considerar a fricativa alveolar em posição de ataque inicial na seleção de palavras para a avaliação fonoaudiológica, uma vez que este contexto silábico favorece a identificação perceptivo-auditiva do ceceio pelo avaliador, além de contribuir para a identificação do paciente sobre este desvio de fala. Conforme sugerido em estudo prévio ${ }^{1}$ é importante a utilização de listas de palavras padronizadas quantitativamente, contendo $o$ mesmo número de palavras em todos os contextos fonético-fonológicos a serem testados, ao verificar e caracterizar a ocorrência de ceceio nas fricativas alveolares, por meio de julgamentos perceptivos. Os achados do presente estudo reforçam a importância do uso de listas de palavras padronizadas quantitativamente incluindo número idêntico de palavras em todos os contextos fonético-fonológicos testados, ao se verificar a ocorrência de ceceio tanto em consoantes fricativas alveolares e quanto pós-alveolares.

No presente estudo, observou-se, ainda, aumento significante do ceceio para a fricativa alveolar em posição de ataque inicial quando comparada somente à coda medial. Essa diferença de julgamento a favor do ataque silábico pode ser explicada, possivelmente, devido às características de produção dessa estrutura silábica. Ou seja, a posição de ataque silábico corresponde ao momento de intensificação da força muscular na produção de uma sílaba, resultando, consequentemente, num aumento de duração e intensidade, tornando-a mais saliente perceptivamente ${ }^{22}$. Estudo prévio utilizando-se de análise acústica indicou duração maior da fricativa [s] quando produzida em posição de ataque do que em coda, para adultos falantes do português brasileiro, com fala típica ${ }^{15}$. Neste sentido, espera-se que a mesma relação ocorra na presença do ceceio, em que valores 
maiores de duração em [s] seriam esperados quando esta consoante se encontra em posição de ataque silábico. Como consequência, uma maior proeminência do ruído turbulento seria esperado diante de [s] quando produzido com duração maior (ou seja, na posição de ataque silábico), sendo portanto mais perceptível aos ouvintes neste contexto silábico.

Observou-se, também, maior ocorrência do ceceio na fricativa alveolar quando comparada com fricativa pós-alveolar, ambas na posição inicial da palavra. $O$ aumento do ceceio para a fricativa alveolar foi significante quando comparada à fricativa pós-alveolar, indicando que, a partir da avaliação perceptivo-auditiva, o ceceio pode ser mais facilmente identificado quando o mesmo encontra-se na fricativa alveolar. A literatura reporta que os fricativos surdos e, principalmente, o fonema /s/, são as produções mais variáveis intra e inter-falantes ${ }^{23}$. Além disso, as fricativas alveolares apresentam energia concentrada em frequências mais altas quando comparadas às pós-alveolares, fato que pode contribuir para a identificação de desvios na produção nas fricativas alveolares, a partir da percepção auditiva. A literatura ainda reporta que estudos envolvendo a identificação das fricativas, a partir de manipulações do material acústico (com a aplicação de filtros de energia ou utilização de fala sintética) mostram que a identificação da fricativa alveolar parece estar na dependência de picos de energia acima de $5 \mathrm{KHz}$, enquanto a identificação da pós-alveolar estaria na dependência de picos de energia por volta de $2,5 \mathrm{KHz}^{2}$. Além disso, um estudo envolvendo as fricativas desvozeadas (alveolar e pós-alveolar), em posição de ataque silábico, produzidas por crianças brasileiras com aquisição fonológica típica e desviante, mostrou que a fricativa alveolar apresenta frequências de ressonâncias mais altas do que a pós-alveolar, fato constado nos parâmetros acústicos pico espectral e momentos espectrais (centróide e assimetria) ${ }^{14}$. Estes dados podem justificar as diferenças observadas na identificação do ceceio nas fricativas alveolar e pós-alveolar uma vez que o mesmo pode ser mais saliente (e, portanto, mais percebido) em [s].

De acordo com os achados do presente estudo, observa-se não haver relação estatisticamente significante entre a ocorrência do ceceio e co-articulação antecipatória com as vogais do extremo vocálico, a partir do julgamento auditivo, concordando com achados reportados previamente 1 . A literatura pesquisada aponta que algumas vogais facilitaram a produção do [s], embora este dado não tenha sido comprovado estatisticamente, resultando em menor ocorrência de ceceio quando a fricativa alveolar co-articulava com vogal posterior. Tal fato também foi observado no presente estudo.
Ainda que não estatisticamente significante, a ocorrência do ceceio foi menor para a vogal $[u]$ na fricativa alveolar, quando julgada perceptivamente. Para fins clínicos, diferenças do deslocamento da língua, do ponto articulatório da fricativa em relação à vogal seguinte, podem ser levadas em consideração no estabelecimento da terapia. Considerando que um menor deslocamento da língua seria necessário para a produção de alveolar, diante de vogal anterior, enquanto um maior deslocamento seria necessário para a produção da fricativa, diante da vogal posterior, a escolha da vogal poderia favorecer tanto a produção quanto a percepção dos segmentos fricativos.

Um estudo que objetivou verificar a interferência de fatores linguísticos em consoantes fricativas produzidas por adultos norte-americanos, sem problemas de fala, a partir da análise de parâmetros acústicos de duração, apontou para a influência da vogal na duração das consoantes fricativas ${ }^{24}$. Futuros estudos envolvendo análise acústica podem contribuir para o entendimento da influência da vogal no ceceio, ainda que tais diferenças não tenham sido resgatadas auditivamente, ao se considerar os resultados do presente estudo. Estudos apontaram para a necessidade de se levar em conta a vogal que acompanhará o segmento a ser analisado acusticamente, na medida em que a produção de fala varia em função da vogal adjacente. Por exemplo, a análise acústica da produção do [s] varia em função da vogal que acompanha este segmento ${ }^{25}$.

De forma geral, a comparação dos achados do presente estudo com estudos prévios torna-se complexa devido a diferenças metodológicas empregadas entre os estudos, incluindo: 1) amostras de fala utilizadas; 2) tonicidade da sílaba; 3) concordância entre os juízes, e 4) julgamentos realizados.

Na presente pesquisa, as amostras de fala foram constituídas de palavras dissílabas paroxítonas que combinavam fricativas coronais com vogais do triângulo vocálico inseridas em uma frase veículo. Já estudos prévios utilizaram de fala espontânea, fala dirigida, repetição de palavras e frases, com e sem recorrência da fricativa alveolar, ao estabelecer a ocorrência do ceceio em crianças ${ }^{4,6}$. Em um desses estudos, no entanto, verificou-se que a produção da fricativa alveolar variou para uma mesma população, de acordo com a amostra de fala produzida ${ }^{4}$, com a presença de ceceio identificada na conversa espontânea. Estes achados apontam para a importância de se considerar a amostra de fala utilizada ao se analisar a ocorrência do ceceio. Um estudo, ${ }^{1}$ em particular, utilizou uma amostra controlada para verificar a influência do contexto fonético-fonológico 
na caracterização do ceceio. Neste estudo, privilegiou-se o fone [s] seguido das sete vogais do Português Brasileiro, em sílabas tônicas e átonas, nas posições de ataque (inicial e medial) e coda (medial e final), sendo que este fonema constituía as palavras dissílabas ou trissílabas nomeadas por crianças e adultos com má-oclusão. Diferenças metodológicas entre o referido estudo e a presente pesquisa (que incluiu somente dissílabas paroxítonas associadas às vogais do triângulo vocálico, produzidas por pré-escolares) dificultam comparações da ocorrência do ceceio, ainda que ambos os estudos tenham utilizado contextos de fala controlados.

Quanto à tonicidade da sílaba, os resultados do presente estudo diferem daqueles reportados previamente, em que se observou uma diminuição significante do ceceio nas posições de ataque (inicial+ medial) quando comparadas com as posições coda (medial+final) ${ }^{1}$. No presente estudo, foram selecionadas fricativas alveolares em posição de ataque inicial ou coda medial, em palavras dissílabas paroxítonas, o que pode justificar as diferenças entre o presente estudo e o reportado na literatura ${ }^{1}$. Além disso, o uso da frase veículo pode ter influenciado a produção do ceceio em fricativas na posição de ataque inicial, divergindo dos resultados de estudo prévio ${ }^{1}$ que julgou palavras isoladas.

A ocorrência do ceceio no presente estudo também pode ter sido influenciada pelos procedimentos metodológicos envolvendo juízes para se considerar presença versus ausência do ceceio. Assim como em estudo prévio ${ }^{11}$, a análise dos dados da presente pesquisa foi feita a partir dos resultados obtidos para a concordância intra e inter juízes. Em relação à concordância inter juízes, estudos prévios consideraram, ao verificar a ocorrência do ceceio na população estudada, concordância de duas avaliadoras no momento da avaliação ${ }^{1}$, concordância da maioria dos juízes em gravações realizadas ${ }^{11}$ ou, ainda, o julgamento de um único juiz ${ }^{4}$. Verifica-se, então, que a literatura aponta variações nos procedimentos metodológicos envolvendo juízes para interpretar a ocorrência do ceceio. No presente estudo optou-se por uma metodologia mais conservadora para a análise dos dados excluindo-se as amostras com menos de $100 \%$ de concordância entre os três juízes, uma vez que o número de repetições gravadas permitiu tal análise. Vale ressaltar que os achados do presente estudo poderiam variar, com um aumento da ocorrência do ceceio para o total das amostras de fala produzidas, caso o procedimento metodológico incluísse a concordância da maioria dos juízes.

Outro fator a ser considerado para explicar as diferenças entre o presente estudo e o da literatura ${ }^{1}$ diz respeito ao tipo de julgamento realizado. No presente estudo, a influência do contexto silábico da palavra no julgamento do ceceio foi feito a partir de avaliação perceptivo-auditiva, diferindo de estudo prévio $^{1}$ que investigou a presença ou ausência de ceceio a partir de informações perceptivo-auditivas e visuais. A literatura ${ }^{26}$ aponta para as contribuições das informações linguísticas e visuais, aliadas às informações acústicas, na percepção apurada dos fones fricativos surdos, uma vez que os mesmos são produzidos com grande turbulência aérea, são constituídos por frequências altas, e com uma articulação de certa forma visível, utilizando-se de lábios e língua, o que auxilia o ouvinte na percepção destas fricativas. Assim, informações auditivas somadas às informações visuais podem ter favorecido a identificação do ceceio no fone [s], conforme observado em estudo prévio.

Estudos futuros visando comparar o ceceio a partir de informações perceptivo-auditivo e perceptivo-auditivo/visual, em amostras de fala idênticas, com populações homogêneas, se fazem necessário. A literatura aponta para a importância em se considerar como os desvios são julgados para fins clínicos e de pesquisa ${ }^{27}$. Um estudo reportou que embora não tenham sido encontradas diferenças estatisticamente significantes entre os julgamentos feitos a partir de material audio e audio/vídeo gravados, observou-se uma tendência das análises de vídeo em resultarem julgamentos mais críticos das características consonantais da fala ${ }^{28}$. Além disso, os resultados de um estudo que investigou particularmente as contribuições da semântica e das informações faciais para o reconhecimento dos fones fricativos surdos da língua inglesa, por adultos com audição normal, sugeriram que a percepção desses fones deriva de uma combinação de informações acústicas, linguísticas, e visuais ${ }^{26}$.

Ainda, estudos futuros que forneçam informações sobre a produção de consoantes fricativas, a partir de medidas instrumentais, podem ampliar os conhecimentos sobre a fala de crianças com e sem alterações oclusais. Conforme reportado na literatura internacional, o uso de avaliações instrumentais para a obtenção de medidas de contato e deslocamento da língua pode colaborar no entendimento da produção de consoantes fricativas (vozeadas e desvozeadas) produzidas por adultos ${ }^{29} \mathrm{e}$ crianças com e sem interposição lingual ${ }^{30}$.

De forma geral, as informações derivadas do presente estudo podem contribuir na prática clínica uma vez que apontam que o ceceio pode ser mais facilmente percebido pelo falante e/ou avaliador, quando o mesmo ocorre na fricativa alveolar e, ainda, em posição de ataque inicial da palavra. Tais informações podem favorecer tanto a avaliação fonoaudiológica, quanto a percepção do 
paciente, no trabalho envolvendo o contraste entre a produção normal e os desvios da produção.

\section{CONCLUSÃO}

Os achados do presente estudo sugerem variabilidade intra-sujeito e inter-palavras, quando o ceceio é identificado por meio de julgamento perceptivo-auditivo, uma vez que, embora presente na produção de todas as crianças, a ocorrência do ceceio foi de $25,23 \%$ para o total das amostras analisadas. Ainda mostra a influência do contexto silábico da palavra no julgamento perceptivo-auditivo, quando se leva em conta as variáveis fricativas (alveolar ou pós-alveolar) e, ainda, a posição que fricativa alveolar ocupa na palavra (posição de ataque inicial e coda medial). Vale ressaltar que, na presença do ceceio, diferenças entre a posição de ataque inicial e coda medial seriam esperadas, uma vez que na fala típica, uma duração maior é observada para a fricativa alveolar na posição de ataque inicial. Na presença do ceceio, uma maior proeminência do ruído turbulento seria esperada diante de [s] quando produzido com duração maior (ou seja, na posição de ataque silábico). De forma geral estes achados apresentam informações adicionais sobre a influência das características fonéticas e fonológicas na produção e na percepção dos fones fricativos coronais, em particular, os surdos, que integram o sistema fonológico do Português Brasileiro. Tais informações podem contribuir para fins clínicos e de pesquisa na área da Motricidade Orofacial.

\begin{abstract}
Purposes: to investigate the occurrence of lisping during fricative sounds produced by children with malocclusal and to analyze the influence of the syllabic context of the fricative in the perceptual judgment of lisping. Method: this prospective study involved auditory perceptual identification of lisping by three experienced speech-language pathologists who judged 428 recorded words produced by 15 children (mean age of $5 \mathrm{y} 1 \mathrm{~m}$ ). The words included alveolar and post-alveolar unvoiced fricative consonants, produced in initial word position followed by [i, a, u] vowels in the stressed position. Intra (almost perfect) and inter (total, 100\%) judgments were obtained before analyzing the data. Results: although all studied children presented lisping at least during one fricative production, it was identified in $25,23 \%$ of the recording analyzed words. A significant increase in lisping was observed for: (a) alveolar fricative in the initial word position $(p<0.001)$, (b) alveolar fricative in the initial word position, in relation to the medial coda $(p=0.001)$ and (c) alveolar fricative in relation to post-alveolar fricative $(p<0.001)$. There was no significant decrease in the lisping in relation to co-articulated vowels. Conclusion: the occurrence of lisping depends on the syllabic context (with more occurrence in alveolar fricative in initial word position), therefore, this context should be considered for clinical and research purposes.
\end{abstract}

KEYWORDS: Speech; Child; Child, Preschool

\section{REFERÊNCIAS}

1. Leite AF, Silva SB, Britto ATBO, Di Ninno CQMS. Caracterização do ceceio em pacientes de um Centro Clínico de Fonoaudiologia. Rev Soc Bras Fonoaudiol. 2008; 13(1):30-6.

2. Kent RD, Read C. The acoust analysis of speech. San Diego: Singular Publishing Group; 1992.

3. Silva TC. Fonética e fonologia do português: roteiro de estudos e guia de exercícios. 9 ed. São Paulo: Contexto; 2007.

4. Monteiro VR, Brescovici SM, Delgado SE. A ocorrência de ceceio em crianças de oito a onze anos em escolas municipais. Rev Soc Bras Fonoaudiol. 2009; 14(2):213-8.
5. Fonseca RA, Tucci TA, Rodriguez RCL, Gomes ICD, Bianchini EMG. A correlação entre ceceio frontal e o crescimento infantil. Rev Soc Bras Fonoaudiol. 2005; 10(4):211-7.

6. Tomé MC, Farias SR, Araújo SM, Schimidt BE. Ceceio interdental e alterações oclusais em crianças de 03 a 06 anos. Pró-Fono. 2004; 16(1):19-30.

7. Comitê de Motricidade Oral (MO). Documento Oficial 03/2003. São Paulo: Sociedade Brasileira de Fonoaudiologia - SBFA. 2003. Ou Sociedade Brasileira de Fonoaudiologia - SBFA. Comitê de Motricidade Oral (MO) [Internet]. Documento Oficial 03/2003 [cited 2005 Dez 08]. Disponível em: http:// www.sbfa.org.br 
8. Sahad MG, Nahás ACR, Scavone-Junior H, Jabur LB, Guedes-Pinto E. Vertical interrincisal trespass assessment in children with speech disorders. Braz Oral Res. 2008; 22(3):247-51.

9. Perlato NM, Nahás-Scocate ACR, Jabur LB, Ferreira RI, Garib DG, Valle-Corotte KM. Correlação entre a presença do ceceio anterior e os tipos de trespasse vertical interincisivo na dentadura decídua. Rev Odont Univ Cid SP. 2009; 21(2):98-103.

10. Suliano AA, Rodrigues MJ, Júnior AFC, Fonte PP, Porto-Carreiro CF. Prevalência de maloclusão e sua associação com alterações funcionais do sistema estomatognático entre escolares. Cad. Saúde Pública. 2007; 23(8):1913-23.

11. Whitaker ME, Freitas JS, Pegoraro-Krook MI, Ozawa TO, Lauris RC, Lauris JP et al. Relationship between occlusion and lisping in children with cleft lip and palate. Cleft Palate-Craniofac J. No prelo 2011.

12. LeBlanc EM, Cisneros GJ. The dynamics of speech and orthodontic management in cleft lip and palate. In: Shprintzen RJ, Bardach J (org). Cleft palate speech management - A multidisciplinary approach. St Louis: Mosby; 1995. 305-26.

13. Pena CR, Pereira MMB, Bianchini EMG. Características do tipo de alimentação e da fala de crianças com e sem apinhamento dentário. Rev CEFAC. 2008; 10(1):58-67.

14. Berti LC, Marino VCC. Marcas hesitativas como constitutivas do processo de aquisição do contraste fônico em crianças com o chamado desvio fonológico evolutivo. Revista do GEL. 2008; 5: 103-21.

15. Haupt C. As fricativas [s], [z], [C] e [3] do português brasileiro. Letras \& Letras. 2008; 24 (1): 59-71.

16. Howard SJ, Heselwood BC. Learning and teaching phonetic transcription for clinical purposes. Clin Ling \& Phon. 2002; 16(5):371-401.

17. Lohmander A, Willadsen E, Persson C, Henningsson G, Bowden M, Hutters B. Methodology for speech assessment in the Scandcleft project-an international randomized clinical trial on palatal surgery: experiences from a pilot study. Cleft Palate Craniofac J. 2009; 46(4):347-62.

http://dx.doi.org/10.1590/S1516-18462012005000102 RECEBIDO EM: 06/09/2011

ACEITO EM: 23/02/2012

Endereço para correspondência:

Viviane Cristina de Castro Marino

Av. Higino Muzzi Filho, 737

Marília - SP

CEP: $17525-900$

E-mail: vivianemarino2@yahoo.com.br
18. Villanueva $P$, Lizana $M L$, Huber $H$, Morán $D$, Fernández MA, Palomino HM. Modificaciones en la articulación de fones en pacientes con aparato ortodóncico fijo lingual. Rev CEFAC. 2007; 9(4):483-9.

19. Berti LC, Pagliuso A, Lacava F. Instrumento de avaliação de fala para análise acústica (IAFAC) baseado em critérios linguísticos. Rev Soc Bras Fonoaudiol. 2009; 14(3):305-14.

20. Boersman $P$, Weenink D. Praat: doing phonetics by computer (Version 5.0.30) [cited 2008 Nov]. Avaliable from: http://www.praat.org/

21. Landis JR, Koch GG. The measurement of observer agreement for categorical data. Biometric. 1977; 33(1):159-74.

22. Cagliari LC. Elementos de fonética do Português Brasileiro. São Paulo: Paulistana; 2007.

23. Cielo CA, Casarin MT. Sons fricativos surdos. Rev CEFAC. 2008; 10(3):352-8.

24. Whitehead RL, Whitehead $B H$, Schiavetti $N$, Metz DE, Farinella K. Effect of vowel environment on fricative consonant duration in speech produced during simultaneous communication. J Commun Dis. 1999; 32(6):423-34.

25. Munson B. Variability in /s/ production in children and adults: evidence from dynamic measures of spectral mean. J Speech Lang Hear Res. 2004; 1:58-70.

26. Jongman A, Wang $\mathrm{Y}$, Kim BH. Contributions of semantic and facial information to perception of nonsibilant fricatives. J Speech Lang Hear Res. 2003; 46(6):1367-77.

27. Howard SJ, Heselwood BC. Learning and teaching phonetic transcription for clinical purposes. Clin Ling \& Phon. 2002; 16:371-401.

28. Sell D, Grunwell P, Mildinhall S, Murphy T, Tremaine AO, Cornish et al. Cleft Lip and Palate Care in the United Kingdom - The Clinical Standards Advisory Group (CSAG) Study. Part 3: Speech Outcomes. The Cleft Palate-Craniofac J. 2001; 38(1):30-7.

29. Mcleod S, Roberts A, Sita J. Tongue/palate contact for the production of /s/ and /z/. Clin Ling \& Phon. 2006; 20(1):51-66.

30. Eslamian L, Leilazpour AP. Tongue to palate contact during speech in subjects with and without a tongue thrust. Europ J Orthod. 2006; 28:475-9. 